
\title{
R Research Soure \\ Research on bogie traction seat crack identification based on OvO multi-feature fusion
}

\section{Qi Chang}

Hunan University of Technology

Yi Liu ( $\nabla$ liuyi_hust@163.com )

Hunan University of Technology https://orcid.org/0000-0002-2008-4796

Lin Li

Hunan University of Technology

Junfeng Man

Hunan University of Technology

Cheng Peng

Hunan University of Technology

Kai Liu

Hunan University of Technology

Han Wu

Hunan University of Technology

\section{Yiping Shen}

Hunan University of Technology

\section{Original Article}

Keywords: Fault diagnosis, Traction seat, Feature extraction, OvO multi-feature fusion

Posted Date: June 22nd, 2021

DOl: https://doi.org/10.21203/rs.3.rs-608144/v1

License: (c) (1) This work is licensed under a Creative Commons Attribution 4.0 International License.

Read Full License 


\section{Abstract}

Aimed at the problems of unsatisfactory feature extraction and low diagnostic accuracy in the identification process during train bogie traction seat operation status, an optimized method of the neural network model of back propagation based on OvO multi-feature fusion is proposed. Firstly, a simulated experimental platform is built to collect vibration signals, and the collected original vibration data are analyzed in time domain, frequency domain and time-frequency. Secondly, the principal component analysis is carried out on the proposed high-dimensional feature sets. Finally, the reduced dimensional features are fused into the optimal feature set based on OvO algorithm. The back propagation neural network model is constructed, and the time domain, frequency domain, timefrequency and optimal feature sets are taken as inputs respectively, and the results of output recognition are compared. The experimental results show that the recognition accuracy of back propagation neural network model based on OvO multi-feature fusion is higher, and the running state of bogie traction seat can be recognized accurately.

\section{Full Text}

This preprint is available for download as a PDF. 